\title{
FOUR CASES OF DUODENAL ULCERATION IN CHILDREN SIMULATING ACUTE APPENDICITIS
}

\author{
BY \\ D. G. WILSON CLYNE, M.A., B.M., B.Ch., M.R.C.O.G. \\ Obstetric and Gynaecological Registrar, Charing Cross Hospital; \\ Surgeon, Emergency Medical Service \\ and \\ J. RABINOWITCH, M.B., B.S. \\ Medical Officer, Emergency Medical Service.
}

The general impression in this country appears to be that duodenal ulceration is an extremely rare condition in childhood. Recent experiences do not entirely corroborate this opinion, as duodenal ulceration has been diagnosed in young children in no fewer than four cases during the past year at one Emergency Medical Service Sector Hospital.

All these patients were sent into hospital as cases of acute appendicitis and this diagnosis appeared correct clinically. An accurate history was difficult to obtain in such young children; the presence of a temperature, a raised pulse, a furred tongue, pain and tenderness in the right iliac fossa made laparotomy imperative. The removal of normal appendices suggested that further investigations were desirable. Accordingly fractional test meals followed by barium meal examinations were carried out in each case, with results which will be discussed.

\section{Case reports}

Case 1. B.M., a boy, aged five years, was admitted with a history of acute central abdominal pain, which had started twelve hours previously. Later, during the day, the pain was referred to the right iliac fossa. There was no

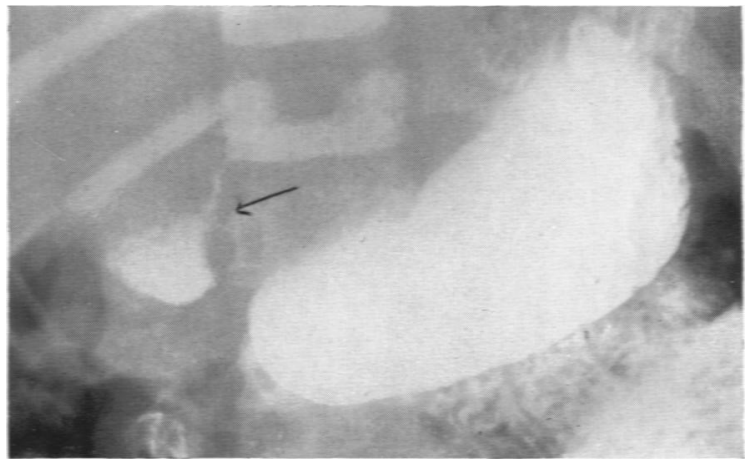

FIG. 1.- Case 1. 
nausea or vomiting. For several days the child's appetite had been poor: there was no history of constipation or diarrhoea.

ON EXAMINATION.-Temperature $100 \cdot 6^{\circ} \mathrm{F}$. : pulse 116 . Child answered questions sensibly and did not look very ill. There was generalized guarding all over the abdomen with marked tenderness in the right iliac fossa, the right loin and the upper part of the right groin. Chest and urine examinations revealed no abnormality. Laparotomy was performed, but as the findings were inconclusive it was decided to continue investigations. Owing to the child's age it was not considered practicable to perform a test meal: investigations in this case are limited to a barium meal and are therefore incomplete. Barium meal result (fig. 1): - The stomach is normal in appearance: it does not empty as rapidly as it should, there being a slight residue at six hours. The duodenal cap shows distinct signs of ulceration, and in view of the absence of abnormality elsewhere, this must be the diagnosis.'

Treatment was then continued on medical lines for four weeks, the child's symptoms subsiding completely after a few days.

Case 2. S.M., aged thirteen years, was admitted with the diagnosis of acute appendicitis, with a vague history of pain in the right iliac fossa. Temperature $99^{\circ}$ F.: pulse 100 . No tenderness on examination. Rectal examination: nothing abnormal detected. Chest and urine: no abnormality. Operation was not considered necessary. On the following day, however, the temperature rose to $100 \cdot 4^{*} \mathrm{~F}$., with a pulse rate of 110 , and there was definite rigidity and tenderness in the right iliac fossa. There was still no tenderness per rectum. Operation was now considered advisable, but a normal appendix was found.

The following investigations were performed: Chest x-ray: no abnormality. Leucocyte count 11,000 per c.mm. Urine: no crystals, casts or organisms.

Fractional test MEAL (fig. 2).--Resting juice 83 c.c. with a total acidity of 45 on the Ewald scale (i.e. $0 \cdot 16$ per cent. $\mathrm{HCl}$ ). Free $\mathrm{HCl}$ was 30 , equivalent to $0 \cdot 1$ per cent. $\mathrm{HCl}$. The total acidity fell to 5 after half an hour when the

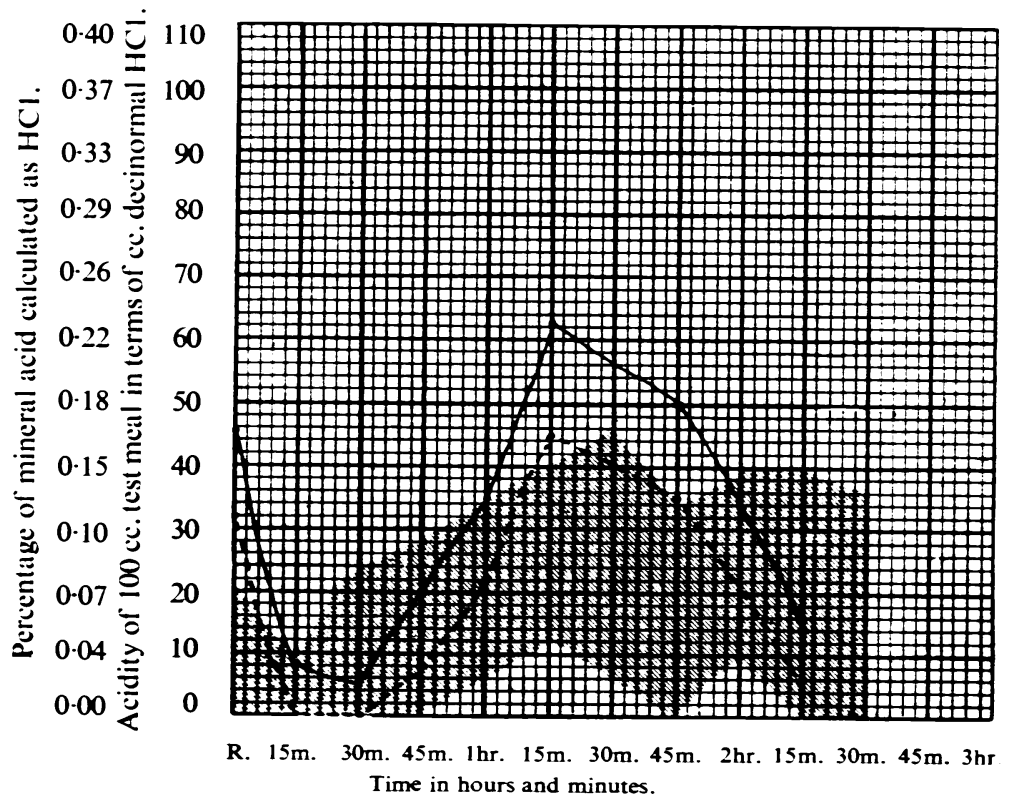

FIG. 2-Case 2. 
free $\mathrm{HCl}$ content was nil. Both acidity curves rose steeply and at $1 \frac{1}{4}$ hours reached a maximum of 65 and 45 respectively. The readings fell equally rapidly to 15 and 5 after $2 \frac{1}{4}$ hours. A microscopic examination of the resting juice revealed a few squamous epithelial cells and also a few partly digested pus cells. Traces of mucus were present in the resting juice, and after one hour. Starch was still present after $2 \frac{1}{4}$ hours. Bile appeared after $1 \frac{3}{4}$ hours. Blood was absent throughout.

BARIUM MEAL (fig. 3) showed a normal stomach. The duodenal cap failed

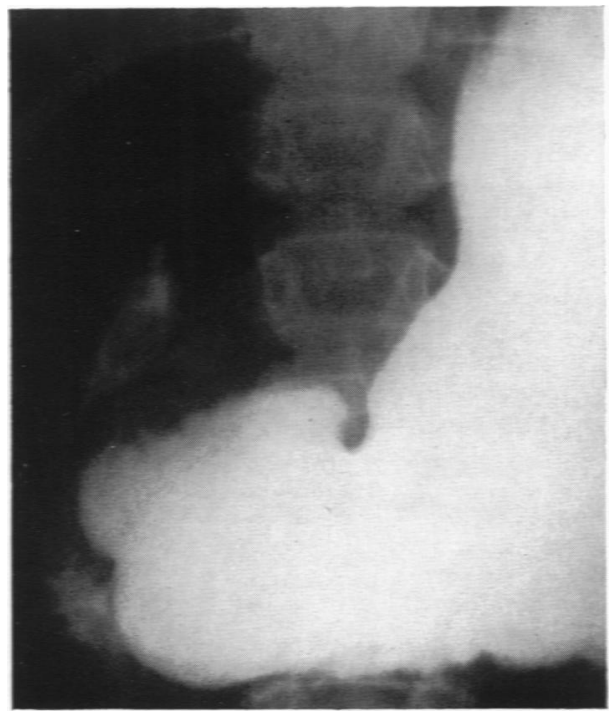

Fig. 3.-Case 2.

to fill but was not tender. The appearances strongly suggest recent duodenal ulceration.

After three weeks of intensive medical treatment the barium meal was repeated, and it was found that the deformity of the duodenal cap still persisted.

Case 3. B.H., a boy, aged seven years, was admitted with symptoms simulating acute appendicitis. He had vomited once on the same day, having lost his appetite several days before admission. On admission the temperature was $102 \cdot 2^{\circ} \mathrm{F}$., and the pulse 130 . He also complained of pain on micturition, but was not tender in the loins or over the bladder. He was, however, rather tender per rectum on the right side. The urine and chest showed no abnormality. He looked flushed, his tongue was furred and he seemed to be in great distress. Examination of the abdomen revealed marked tenderness in the right iliac fossa, and epicritic sensibility was increased on the right side of the abdomen.

Laparotomy was performed, and in view of the negative findings, once again further investigations were deemed necessary.

Leucocyte count: 17,000 per c.mm. Sedimentation rate $24 \mathrm{~mm}$. per hour. Chest $\mathrm{x}$-ray negative. Urinary culture and guinea-pig inoculation showed no organisms or tubercle bacilli. Benzidine test for occult blood and spectroscopic examination were negative.

Fractional test MEAL (fig. 4). - The resting juice was 19 c.c. with a total acidity of 11 (i.e. 0.03 per cent. $\mathrm{HCl}$ ) and no free $\mathrm{HCl}$ present. The maximum 
rise occurred after $1 \frac{1}{4}$ hours, namely 35 and 20 respectively, and these levels were maintained until $2 \frac{1}{4}$ hours. Microscopy revealed a few squamous epithelial cells and a fair number of partly digested pus cells. Starch was

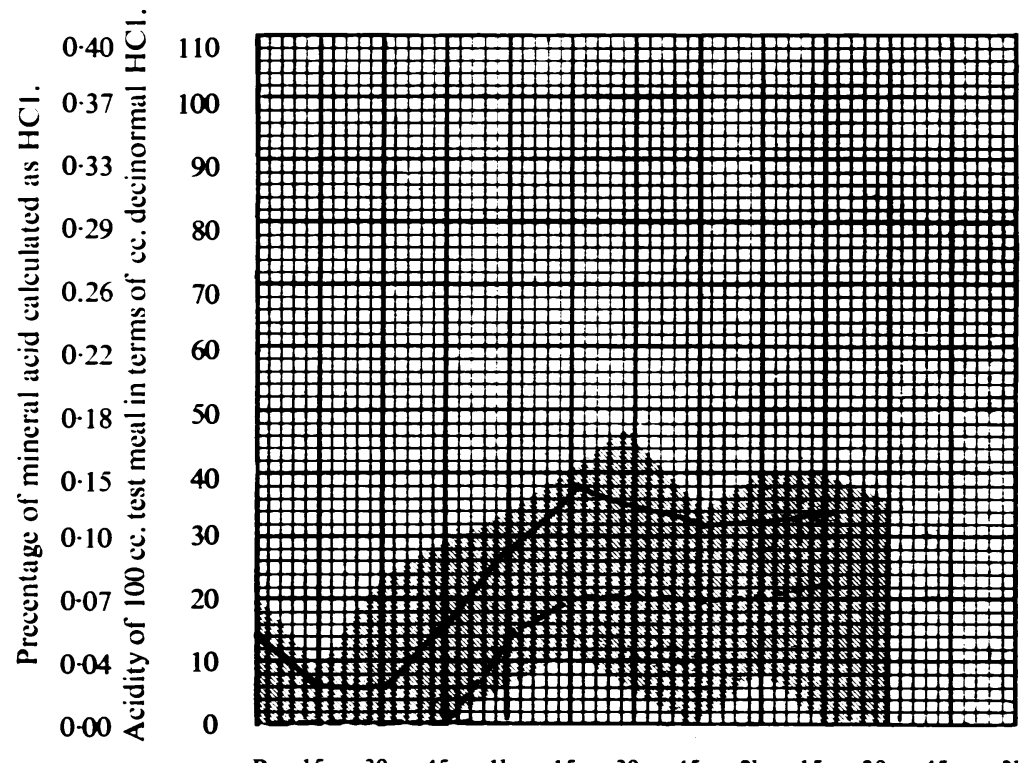

R. $15 \mathrm{~m} .30 \mathrm{~m} .45 \mathrm{~m} .1 \mathrm{hr} .15 \mathrm{~m} .30 \mathrm{~m} .45 \mathrm{~m} .2 \mathrm{hr} .15 \mathrm{~m} .30 \mathrm{~m} .45 \mathrm{~m} .3 \mathrm{hr}$. Time in hours and minutes.

Fig. 4.-Case 3.

still present after $2 \frac{1}{4}$ hours, bile and blood were absent throughout. Mucus occurred only in the resting juice.

BARIUM MEAL (fig. 5).- - Definite evidence of duodenal ulceration, recent,

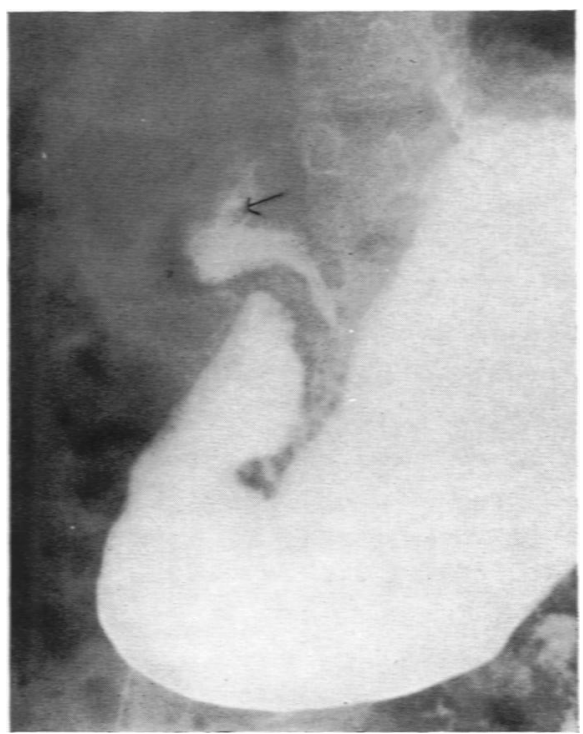

Fig. 5.-Case 3. 
with some mucosal oedema about half-way up the cap. There is a small degree of associated gastritis."

After three weeks' medical treatment there was persistent scarring of the duodenal cap, suggesting fibrosis not oedema.

Case 4, P.C., aged seven years, admitted with abdominal pain and constipation. He had vomited once before admission, his tongue was furred, he was tender in the right iliac fossa, and a positive Rovsing sign was elicited. Per rectum he was extremely tender on the right side. His temperature was 99.6 $\mathrm{F}$. and his pulse 96. He appeared flushed and was rather distressed. At laparotomy a normal appendix was removed and, therefore, further investigations were carried out. Urine and chest: nothing abnormal.

Fractional test MEAL (fig. 6).- - There was no resting juice in the fractional

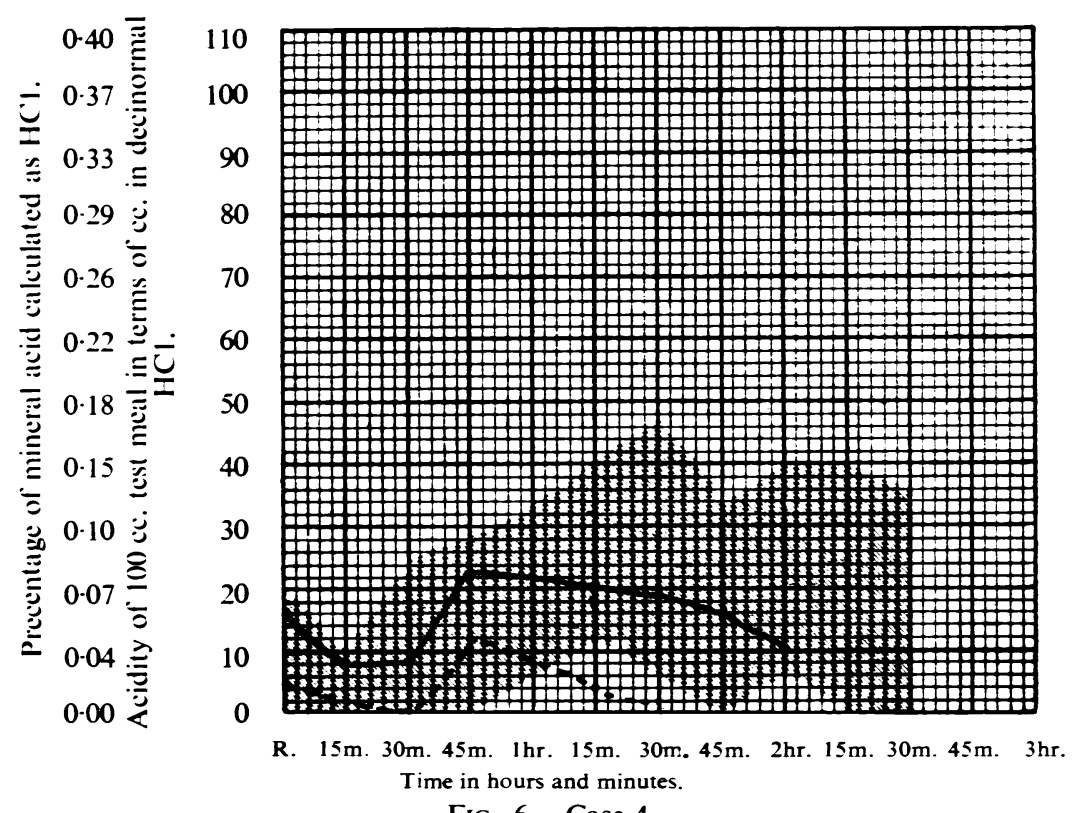

FIG. 6.-Case 4.

test meal. The total acidity remained low throughout, only rising to 23 after one hour and slowly dropping to 20 after one-and-a-half hours. The free $\mathrm{HCl}$ content never rose beyond 10 . Microscopy revealed similar features to the cases previously described, namely squamous epithelial cells and a few pus cells. Bile and blood were absent.

BARILM MEAL (fig. 7).- - The duodenal cap shows a persistent slight deformity caused by scarring from a small duodenal ulcer. No evidence of activity now or delay in emptying. After three months of strict medical treatment, the appearances of the duodenal cap were those of cicatrization from a small ulcer on either the posterior or anterior wall, with no delay in emptying and no general deformity. There was a small excess of secretion in the stomach.

\section{Discussion}

It is obvious that no definite conclusions can be reached from so short a series of cases, and the main object in publishing them is to draw attention to the possibility of such a diagnosis in young children. 
The first investigation of duodenal ulcers in children was carried out on a large scale by Theile (1919), who classified them in three groups:

Neonatal: Secondary to thrombosis, or associated with melaena neonatorum of unknown origin.

Infancy: Secondary to marasmus, tuberculosis, syphilis, scarlet fever, burns, uraemia, trauma and inflammations.

Childhood: Primary chronic round ulcer.

The first two groups contain a large number of cases, but little attention appears to have been directed to the third group occurring in childhood. In 1920 Moynihan stated that chronic peptic ulcer could often be traced back to the age of ten years and earlier. Proctor (1925) investigated the histories of

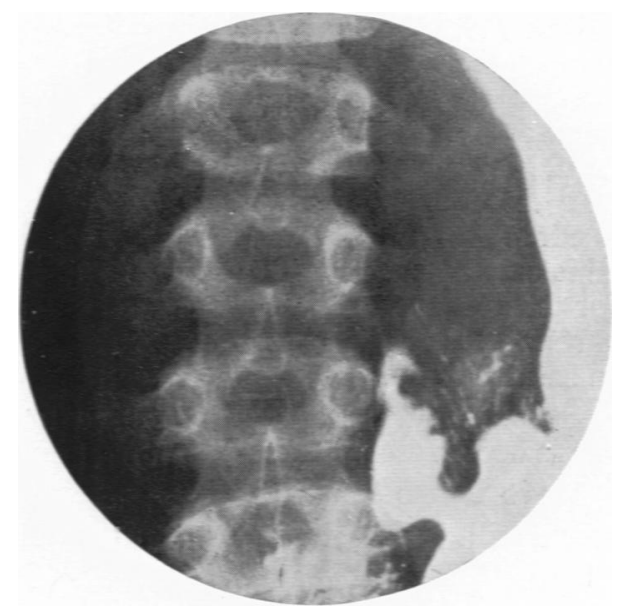

Fig. 7.-Case 4.

a thousand cases of duodenal ulcer and a thousand cases of gastric ulcer. He found that twenty-six cases of duodenal and sixteen of gastric ulcer gave a history which dated back to childhood. On the other hand, only three cases of duodenal ulcer in children were admitted to the Mayo clinic for treatment out of a total of ten thousand cases of peptic ulceration.

Hirsch (1935) reports after extensive statistical survey of 10,845 cases of peptic ulcer that 0.3 to 1.0 per cent. occurred in children, but most of these occurred in children of the youngest age group. Berglund (1928) reporting from a Swedish Children`s Hospital concurred with this view, and stated that 1.4 per cent. of all post-mortem examinations during the first year of life reveal a duodenal ulcer. At a later age group Sturtevant and Shapiro (Conklin, 1941) reporting on 7,219 necropsies found that there were five cases of gastric ulcer in children.

In this country Hurst and Stewart (1929) in an analysis of two hundred cases of peptic ulceration found none in the first decade, but eight occurred in the second. In the United States, on the other hand, several more recent surveys have been made; Bloch, Bronstein and Serby (1932) reported four cases aged five, nine, eleven and thirteen years respectively. The first three were girls. Burdick (1940) reported ten cases in children. Moore (1941) in Canada had eight cases, and his conclusions will be mentioned later. In Italy, Toro (1937) described three cases and Bignami (1939) four cases, diagnosed radiologically. In Russia, Gerasimov (1939) reported a case of perforation of a duodenal ulcer in a child aged three-and-a-half. 
In Great Britain, Smyth, Crymble and Allen (1934) mentioned a case of duodenal ulcer occurring in a girl of ten. Miller and Gage (1930) found a cicatrizing chronic duodenal ulcer in a girl of seven. The sex incidence of ulcers in children was investigated by Saltzstein, Farbman and Sandweiss (1940), who found 105 cases in the literature up to 1940, most of them in infants. From their records they came to the conclusion, that whereas peptic ulcer is by far more prevalent in adult men than women, its occurrence among children was spread equally over both sexes.

As far as clinical features are concerned Kennedy (1933) stated that in children below the age of ten the familiar syndrome of an uncomplicated ulcer is absent. Two out of his six cases had appendicectomies performed. He thought that it was neither necessary nor desirable to determine the gastric acidity in children. John (1938) described a rather unusual case, in which a child of six was admitted with a temperature of $103^{\circ} \mathrm{F}$. and a pulse of 120 , a coated tongue, with tenderness but no rigidity in the right iliac fossa. Appendicectomy was performed and two stercoliths were found in the appendix. A few days later the child died from a haematemesis due to a large ulcer crater in the first part of the duodenum. Moore (1941) has seen eight cases of duodenal ulcer in children, three of these being admitted as cases of acute appendicitis. Six of his cases had abdominal tenderness and nearly all of them had either vomited or felt sick before admission. He also mentions that he found that gastric analyses were inconclusive. His cases were treated medically and found to respond satisfactorily.

There appears to have been a great increase in the number of cases diagnosed since Proctor of the Mayo Clinic stated in 1925 that only nineteen cases of primary duodenal ulcer in children had been described in the literature.

\section{Conclusions}

As far as the new cases here described are concerned, the following facts seem worthy of mention.

History.-There was no typical prolonged history comparable with the adult symptoms of pain occurring after food. One of the cases, however (the girl of thirteen), is still complaining of occasional pain, which has now, four months after the start of medical treatment, begun to bear some relation to meals.

In all cases there was a history of only a few hours' pain before admission. Nausea or vomiting were present in three cases, but had not occurred more than once in any one case.

Physical signs. - (1) Temperature and pulse were raised in all cases. The temperature varied from $99.0^{\circ}$ to $102 \cdot 2^{\circ} \mathrm{F}$. The pulse rate appeared to be increased approximately in proportion to the temperature.

(2) Tenderness was localized in three cases to the right iliac fossa only, and in one case occurred in both iliac fossae.

(3) Rigidity was present in two cases ; this was not confined to the right side only, but extended to the left side as well.

(4) Tenderness per rectum was found in all cases. But this cannot be conclusive, as it is difficult to be certain whether the examination is not merely causing discomfort.

Special tests.-1) A leucocyte count of 17,000 per c.mm. occurred in one 
case, but appears to be quite irrelevant to the ulcer condition. The leucocyte counts in the other cases were quite inconclusive.

(2) Gastric analyses.-Out of three cases in which these were performed, one had a normal curve; one only had a raised acidity (the girl), and even here the readings are hardly above the normal limit: the third had a very low acidity curve. In the main we agree with Moore and Kennedy, who both state that gastric analyses are inconclusive.

(3) Barium meal.-All the ulcers occurred in the first part of the duodenum and varied from mere mucosal swelling to well formed craters surrounded by mucosal oedema.

After medical treatment the deformity still persisted, having become permanent owing to fibrosis and thickening in two of our cases.

Thanks are due to Dr. Stewart Russell Reynolds for his co-operation in carrying out the barium meal examinations and allowing the reproduction of his reports on the $\mathrm{x}$-ray pictures.

\section{REFERENCES}

Berglund, N. (1928). Acta Paediatr., Stockh., 8, 323.

Bignami, G. (1939). Radiolog. med., Torino, 26, 394.

Bloch, L., Bronstein, I. P., and Serby, A. M. (1932). J. Amer. med. Ass., 98, 2184.

Burdick, W. F. (1940). J. Pediat., 17, 654.

Conklin, C. B. (1941). Int. Clin., 2, 79.

Gerasimov, M. I. (1939). Khirurgiva, 12, 122.

Hirsch, W. (1935). Mschr. Kinderheilk., 63, 429.

Hurst, A. F., and Stewart, M. J. (1929). Gastric and duodenal ulcer, London.

John, R. W. (1938). Lancet, 1, 433.

Kennedy, R. L. J. (1933). J. Pediat., 2, 641.

Miller, R., and Gage, H. C. (1930). Arch. Dis. Childh., 5, 83.

Moore, O. M. (1941). Canad. med. Ass. J., 44, 462.

Moynihan, B. (1920). Brit. med. J., 2, 99.

Proctor, O. S. (1925). Surg. Gynec. Obstet., 41, 63.

Saltzstein, H. C., Farbman, A. A., and Sandweiss, D. J. (1940). Endocrinology, $27,400$.

Smyth, M. B., Crymble, P. T., and Allen, F. M. (1934). Brit. med. J., 1, 1074.

Theile, P. (1919). Ergebn. inn. Med. Kinderheilk., 16, 302.

Toro, N. (1937). Pediatria, 45, 904. 